\title{
Surface-active element transport and its effect on liquid metal flow in laser-assisted additive manufacturing
}

Article in International Communications in Heat and Mass Transfer · August 2017

DOI: 10.1016/j.icheatmasstransfer.2017.06.007

CITATION

1

4 authors, including:

Zhengtao Gan

Northwestern University

5 PUBLICATIONS 12 CITATIONS

SEE PROFILE

\section{Xl He}

Chinese Academy of Sciences

54 PUBLICATIONS 765 CITATIONS

SEE PROFILE
READS

131

\section{Gang Yu}

Chinese Academy of Sciences

43 PUBLICATIONS 619 CITATIONS

SEE PROFILE

Some of the authors of this publication are also working on these related projects: 


\title{
Surface-active element transport and its effect on liquid metal flow in laser- assisted additive manufacturing
}

\author{
Zhengtao Gan, Gang Yu*, Xiuli He*, Shaoxia Li \\ Key Laboratory of Mechanics in Advanced Manufacturing, Institute of Mechanics, Chinese Academy of Sciences, Beijing 100190, China \\ School of Engineering Science, University of Chinese Academy of Sciences, Beijing 100049, China
}

\section{A R T I C L E I N F O}

\section{Keywords:}

Additive manufacturing

Mass transfer

Surface-active element

Fluid flow

\begin{abstract}
A B S T R A C T
During laser-assisted additive manufacturing, the transport phenomena, solidification behavior, and melt pool geometry are affected by base-metal sulfur content and oxygen present in the atmosphere. The role of these surface-active elements during metal-based additive manufacturing is not well understood. In this study, the mass transport of sulfur and its effect on liquid metal convection (Marangoni flow) are examined by using an improved 3D transient heat transfer and fluid flow numerical model. An improved surface tension model is proposed to take into account the influence of sulfur content and temperature at the surface of melt pool. The sulfur mass transport equation is combined with the other conservation equations. The results show that the sulfur redistribution leads to transitional Marangoni flow. The powder addition into the melt pool results in the dilution of sulfur in the melt pool. Increase in mass flow rate and energy input results in decreased temperature coefficient of surface tension. When temperature coefficient of surface tension changes sign from positive to negative, the flow motion transition from inward flow to outward flow occurs. Two predominant types of flow pattern lead to two types of fusion boundaries of deposited track.
\end{abstract}

\section{Introduction}

In laser-assisted additive manufacturing, a deposited layer is obtained through melting metal powder delivered and deposited on the surface of the base metal. Many complicated physical phenomena, such as laser-powder interactions, heat and mass transfer, fluid flow, melting, and solidification are involved in this process [1-3]. Since the Peclet number is on the order of $10^{2}-10^{5}$ in the melt pool in laserassisted additive manufacturing, convection plays a vital role in the heat transport and the melt pool formation [4]. The convection in the melt pool is driven by various driving forces. Marangoni stress has been proven to be the main driving force $[5,6]$. Owing to the spatial gradient of surface tension driven by the temperature or compositional gradients, the Marangoni stress arises on the melt pool surface [7]. The Marangoni stress is defined by the spatial temperature gradient multiply by the temperature coefficient of surface tension on the surface of melt pool.

The content of surface-active elements of group VIA (i.e. oxygen, sulfur, selenium, and bismuth) in the melt pool has an influence on the direction and magnitude of Marangoni stress [8,9]. If surface-active elements are not present in the melt pool, the temperature coefficient of surface tension is negative, and liquid metal flows outwards along the surface of melt pool [8]. If surface-active elements are present in the melt pool, the temperature coefficient of surface tension may become positive depending on the local temperature and the concentration of the surface-active elements $[10,11]$. Oxygen exists generally in atmosphere or shielding gases. The effect of oxygen on Marangoni convection in laser-assisted additive manufacturing has been studied experimentally and numerically $[9,12]$. For most general-quality forged steel, including low-carbon steel, medium-carbon steel and stainless steel, containing sulfur is inevitable due to the metallurgical imperfection [13]. Addition of sulfur-free powder leads to the redistribution of sulfur in the melt pool. However, the influence of sulfur in the base metal on Marangoni flow during laser-based powder deposition has not been fully understood.

Due to high temperatures, the block of metallic powder and spatter, and small dimension of melt pool, experimental observation is difficult [8]. Numerical simulation has previously offered a tool of effective evaluating the transport phenomena in laser-based powder deposition [14-21]. Qi et al. developed a 3D transition numerical model in which fluid flow is solved with an energy equation [14]. The level-set method was used to capture the free surface of the melt pool. He et al. simulated the laser-assisted additive manufacturing processing by a self-consistent mathematical model [15]. The heat transfer, phase changes, mass

\footnotetext{
* Corresponding authors.

E-mail addresses: gyu@imech.ac.cn (G. Yu), xlhe@imech.ac.cn (X. He).
} 
addition, fluid flow were incorporated in the model. Since the addition of powder results in solute redistribution during the laser-assisted additive manufacturing process, the solute transport in the melt pool has been computed by solving the species conservation equations $[16,17]$. The solute transport and composition profiles evolution during singletrack and double-track laser-assisted additive manufacturing have been reported $[16,17]$. In these models, the temperature coefficient of surface tension is assumed to be a constant. Lee et al. considered the temperature-varying temperature coefficient of surface tension in stationary Inconel 718 laser cladding [18]. Two opposing surface flows were found within the melt pool. A transition temperature dividing the two regions has been obtained. Although the relationship between surface tension of liquid metal and both temperature and surface-active element content has been established theoretically [22], this surface tension model has not been introduced into the mathematical model of laser-assisted additive manufacturing.

In this paper, in order to investigate the transitional Marangoni convection in laser-based powder deposition on sulfur-containing base metal, an improved surface tension model is proposed to take into account the influence of sulfur content and temperature at the top of melt pool. The sulfur mass transport equation is also combined with the other conservation equations. The Marangoni flows in the melt pool under various mass flow and energy input are examined. The calculated concentrations of elemental sulfur and melt pool geometry are compared with corresponding experimental results to validate the computational solutions.

\section{Mathematical model}

A numerical model to simulate heat transfer, fluid flow and mass transfer in laser-assisted additive manufacturing has been developed. Fig. 1 shows the physical phenomena in laser-assisted additive manufacturing on the sulfur-containing base metal. The simplifying assumptions are the following $[16,21]$ :

1. The fluid flow in the melt pool is assumed to be Newtonian, laminar and incompressible.

2. The surface tension of liquid metal depends on the temperature and sulfur content at the top of the melt pool.
3. The laser heat flux is assumed to be a Gaussian distribution.

4. The heat flux of the heated powder and the heat loss by evaporation are neglected.

5. The mushy zone where the temperature is between the solidus and liquidus is assumed as a porous medium with isotropic permeability.

6. The concentration distribution of powder flow is assumed to be Gaussian.

7. Powder falling in the region of melt pool is melted immediately. The powder particles are supposed to be at the same temperature as the melt pool and Momentum quantity associated with the powder addition in the melt pool is neglected.

8. There is no diffusion transport in solid phase.

\subsection{Governing equations}

The following equations of continuity, momentum, energy and solutions transport in the workpiece are expressed in Eqs. (1)-(4).

$\frac{\partial \rho}{\partial \mathrm{t}}+\frac{\partial\left(\rho u_{i}\right)}{\partial x_{i}}=0$

$\frac{\partial\left(\rho u_{i}\right)}{\partial \mathrm{t}}+\frac{\partial\left(\rho u_{i} u_{j}\right)}{\partial x_{i}}=\frac{\partial}{\partial x_{i}}\left(\mu \frac{\partial u_{j}}{\partial x_{i}}\right)-\frac{\partial p}{\partial x_{i}}+\frac{\partial}{\partial x_{j}}\left(\mu \frac{\partial u_{j}}{\partial x_{i}}\right)-K_{0} \frac{\left(1-f_{l}\right)^{2}}{f_{l}^{3}+B} u_{i}$

$\frac{\partial\left(\rho c_{p} T\right)}{\partial t}+\frac{\partial\left(\rho u_{i} c_{p} T\right)}{\partial x_{i}}=\frac{\partial}{\partial x_{i}}\left(k \frac{\partial T}{\partial x_{i}}\right)-\frac{\partial \Delta H}{\partial t}-\frac{\partial\left(\rho u_{i} \Delta H\right)}{\partial x_{i}}$

$\frac{\partial(\rho c)}{\partial \mathrm{t}}+\frac{\partial\left(\rho u_{i} c\right)}{\partial x_{i}}=\frac{\partial}{\partial x_{i}}\left(\rho D \frac{\partial c}{\partial x_{i}}\right)$

where $t$ is the time, $u_{j}$ is the $j^{\text {th }}$ component of velocity, $\mu$ is the viscosity, $p$ is pressure, and $T$ is the Temperature, $c_{p}$ is the specific heat, $\rho$ is the density, $k$ is the thermal conductivity, $c$ and $D$ are the concentration and the diffusion factor of the element sulfur. The fourth term in the right side of Eq. (2) represents the frictional dissipation in the mushy zone [23]. $K_{0}$ is the morphology constant of the porous media $\left(10^{7}\right.$ in this study). B is a small number to avoid division by zero $\left(10^{-3}\right.$ in this study). The mass transport of sulfur is calculated based on Eq. (4). $\Delta \mathrm{H}$ is the latent enthalpy content of the fusion, which is given as,

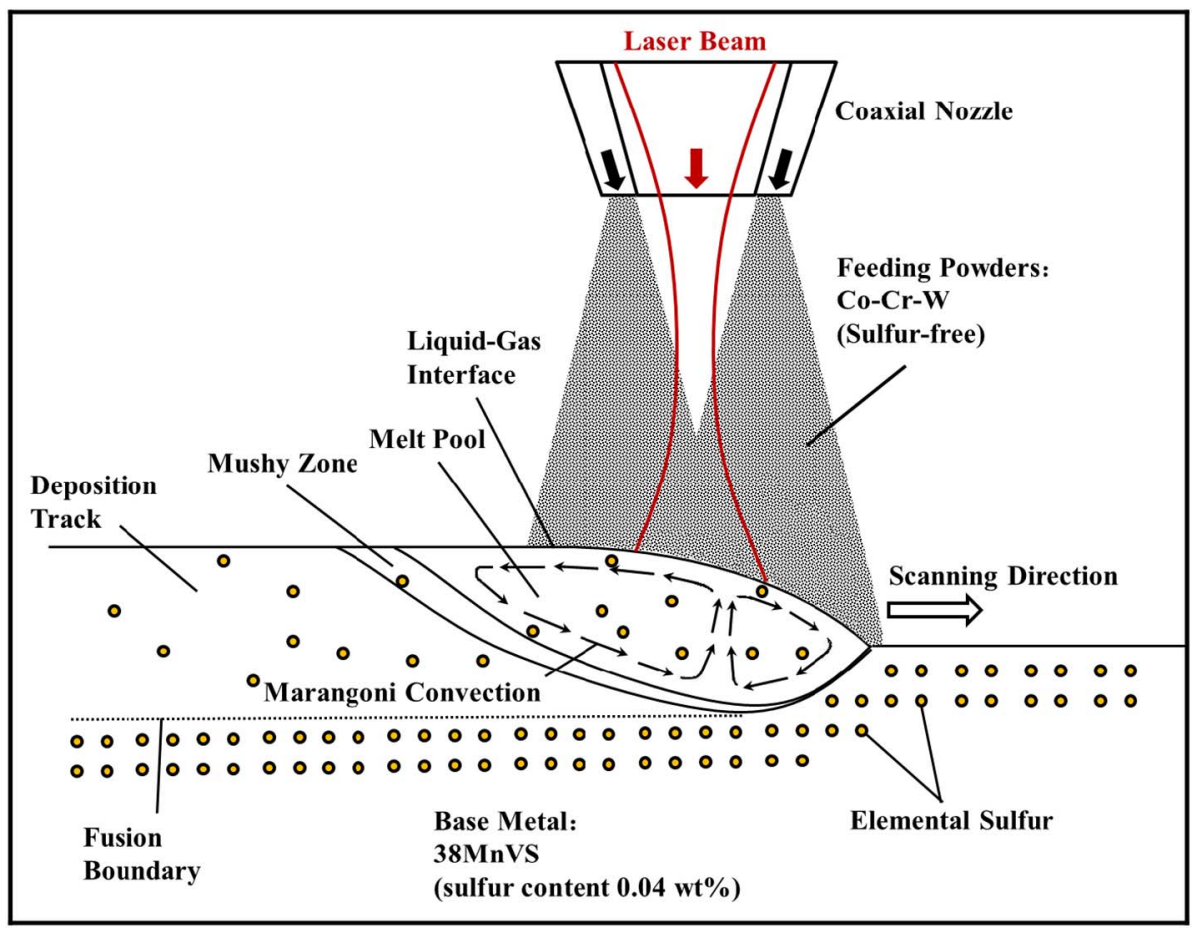

Fig. 1. Modeling Marangoni flow and sulfur mass transport during the laser-assisted additive manufacturing process. 
$\Delta H=L f_{l}$

where the liquid mass fraction $f_{l}$ is defined as,

$f_{l}=\left\{\begin{array}{cc}1, & T>T_{l} \\ \frac{T-T_{s}}{T_{l}-T_{s}}, & T_{s} \leq T \leq T_{l} \\ 0, & T<T_{s}\end{array}\right.$

$T_{l}$ and $T_{s}$ are the liquidus and solidus of substrate, respectively. In the study, the solid and liquid phases are assumed as a continuum media. Assuming that $f$ and $g$ represent the mass and volume fraction, respectively, the physical properties are defined as,

$c_{p}=f_{s} c_{p s}+f_{l} c_{p l}$

$\rho=g_{s} \rho_{s}+g_{l} \rho_{l}$

$k=\left(\frac{g_{s}}{k_{s}}+\frac{g_{l}}{k_{l}}\right)^{-1}$

$D=f_{l} D_{l}$

\subsection{Surface tension of liquid metal}

The surface tension variation at the surface of the melt pool plays an important role in the fluid flow. The surface tension gradient is considered to be a function of the temperature and the concentration of the surface-active element in the solution (sulfur in this study). This function is thermodynamically derived for different binary systems including Fe-S and Co-S by Sahoo et al. [22] as follows,

$\frac{\partial \sigma}{\partial T}=-A-R \Gamma_{S} \ln \left(1+K \alpha_{S}\right)-\frac{K \alpha_{S} \Gamma_{S} \Delta H_{0}}{T\left(1+K \alpha_{s}\right)}$

$K=k_{1} \exp \left(-\frac{\Delta H_{0}}{R T}\right)$

where $\sigma$ is the surface tension of the pure metal at its melting temperature, $A$ is the negative of surface tension temperature coefficient, $R$ is the universal gas constant, $\Gamma_{s}$ is the surface excess at saturation, $k_{1}$ is a constant corresponding to the segregation entropy, $\Delta H_{0}$ is the standard heat of adsorption and $a_{s}$ is the activity of the active element which could be approximated by the sulfur concentration (weight\%) in the solution. The values of the parameters required for the surface tension calculations of Fe-S and Co-S binary systems are given in Table 1. In the evaluation of the surface tension of the ternary solution Fe-Co-S, the modified temperature coefficient of surface tension should be used based on the public literatures $[24,25]$. The variation of the temperature coefficient of surface tension at different temperatures and sulfur concentrations according to the Eq. (11) can be calculated and present in Fig. 2. The isotherms of the temperature coefficient of surface tension are shown in the figure.

\subsection{Boundary and initial conditions}

A Gaussian distribution is assumed as the laser heat flux perpendicularly input at liquid/gas interface, which can be formulated as follow,

Table 1

Data for surface tension calculations [22].

\begin{tabular}{lll}
\hline Property & Fe-S & Co-S \\
\hline $\begin{array}{l}\text { Surface tension } \sigma\left(\mathrm{N} \mathrm{m}^{-1}\right) \\
\text { Negative of coefficient of surface tension for } \\
\text { pure metal do/dT }\left(\mathrm{N} \mathrm{m}^{-1} \mathrm{~K}^{-1}\right)\end{array}$ & $\begin{array}{l}1.943 \\
4.3 \times 10^{-4}\end{array}$ & $\begin{array}{l}1.993 \\
5.7 \times 10^{-4}\end{array}$ \\
$\begin{array}{l}\text { Surface excess at saturation } \Gamma_{s}\left(\mathrm{Kmol} \mathrm{m}^{-2}\right) \\
\quad \begin{array}{l}\text { Constant corresponding to the segregation } \\
\text { entropy } k_{1}\end{array}\end{array}$ & $\begin{array}{l}1.3 \times 10^{-8} \\
\text { Standard heat of adsorption } \Delta H_{0}\left(\mathrm{~kJ} \mathrm{kmol}^{-1}\right)\end{array}$ & $\begin{array}{l}1.6 \times 10^{-8} \\
0.00318\end{array}$ \\
\hline
\end{tabular}

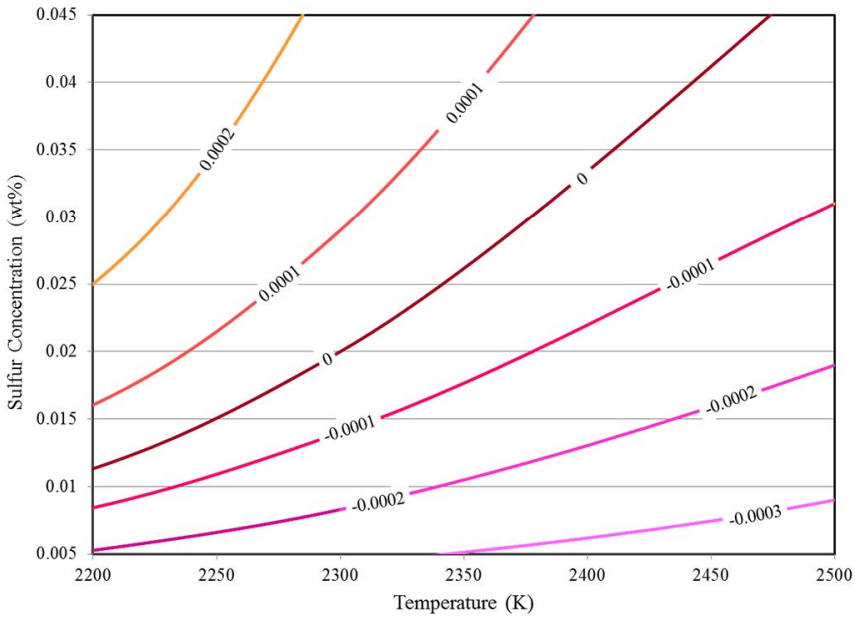

Fig. 2. Variation of the temperature coefficient of surface tension at different temperature and sulfur concentration of the ternary solution Fe-Co-S.

$q_{\text {ener }}=\frac{2 Q^{\prime} \eta_{l}}{\pi r_{b}^{2}} \exp \left(\frac{-2\left(\left(x-V_{s} t\right)^{2}+y^{2}\right)}{r_{b}^{2}}\right)-h_{c}\left(T-T_{0}\right)-\sigma_{b} \varepsilon\left(T^{4}-T_{0}^{4}\right)$

The three terms in the right side represent the energy by the laser beam and the heat loss by convection and radiation, respectively. $Q^{\prime}$ is the attenuated laser power, $\eta_{l}$ is the absorptance of laser energy, $r_{b}$ is the effective laser beam radius, $x$ and $y$ are the distances to the laser beam, $V_{s}$ is the scanning speed, $h_{c}$ is the heat transfer coefficient, $\sigma_{b}$ is the Stefan-Boltzmann constant, $\varepsilon$ is the emissivity, $T_{0}$ is the ambient temperature.

The momentum boundary condition at liquid/gas interface incorporating the capillary force and thermocapillary force are formulated as [15],

$F_{L / G}=\sigma \boldsymbol{n}^{*} \varkappa-\nabla_{s} T \frac{d \sigma}{d T}$

where $\sigma$ is the surface tension, $\boldsymbol{n}^{*}$ is the normal of surface pointing inward to liquid phase, $\kappa$ is the curvature.

The dynamic shape of the melt pool surface is explicitly described by a moving mesh based on an arbitrary Lagrangian-Eulerian method (ALE) [26]. They can be formulated as [27],

$V_{L / G}=\boldsymbol{u n}^{*}+\boldsymbol{V}_{p} \boldsymbol{n}^{*}$

where $\boldsymbol{u}$ is the fluid flow velocity at liquid/gas interface. $\boldsymbol{V}_{p}$ represents the moving velocity of liquid/gas interface due to mass addition. The calculation of $\boldsymbol{V}_{p}$ is given by,

$\boldsymbol{V}_{\boldsymbol{p}}=\frac{2 m_{f} \eta_{m}}{\rho_{m} \pi r_{p}^{2}} \exp \left(\frac{-2\left(\left(x-V_{s} t\right)^{2}+y^{2}\right.}{r_{p}^{2}}\right) \boldsymbol{z}$

where $m_{f}$ is the mass flow rate, $\eta_{m}$ is powder catchment efficiency, $\rho_{m}$ is the density of powder and $r_{p}$ is the mass flow radius, $\boldsymbol{z}$ is unit vector in the $\mathrm{z}$ direction.

The corresponding boundary conditions for concentration equations at the liquid-gas interface are formulated as follow [21],

$q_{i}=\chi_{i} \frac{2 m_{f} \eta_{m}}{M_{i} \pi r_{p}^{2}} \exp \left(\frac{-2\left(\left(x-V_{s} t\right)^{2}+y^{2}\right)}{r_{p}^{2}}\right)$

where $q_{i}$ is the concentration flux of the $i^{\text {th }}$ component of powder, $\chi_{i}$ represents the molar fraction of the $i^{\text {th }}$ component of powder and $M_{i}$ represents the molar mass of the $i^{\text {th }}$ component of powder.

The initial temperature in the workpiece is $293 \mathrm{~K}$. The initial velocity is zero. The initial mass fraction of elemental sulfur in the workpiece is $0.04 \%$. 


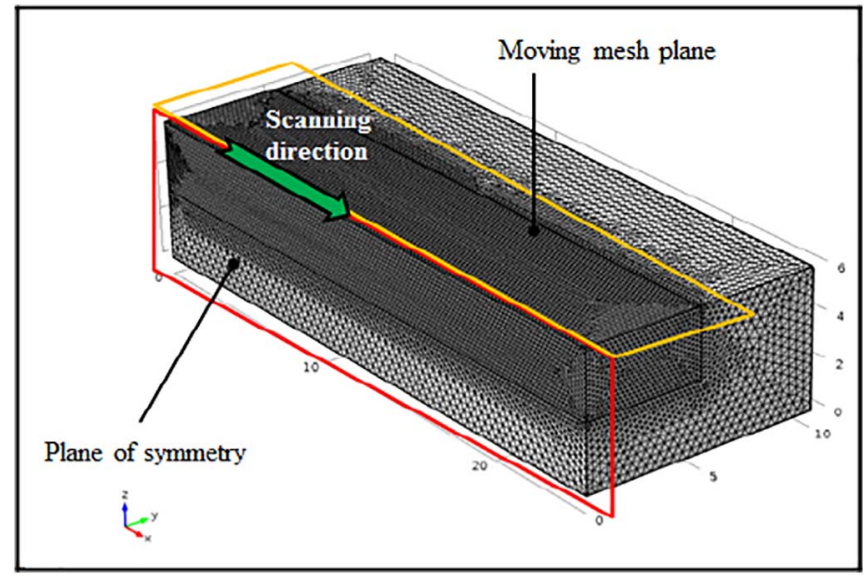

Fig. 3. Schematic diagram of numerical domains.

\subsection{Numerical solutions}

A 3D Cartesian coordinate system is established in the study. Due to the symmetry, only half of workpiece is considered. The basic grid system used in the calculation contains $500 \times 200 \times 180$ grid points. Finer grid spacing is used near the heat source. The minimum grid space along the $x, y$, and $z$ directions are about $50 \mu \mathrm{m}, 45 \mu \mathrm{m}$ and $38 \mu \mathrm{m}$, respectively. This grid system was proved to be grid independent. The unstructured tetrahedral mesh distribution is specified as shown in Fig. 3. A time dependent solver with a maximum time step of $1 \times 10^{-5} \mathrm{~s}$ is employed. The maximum displacement of the interface at one time step should be less than the minimum grid spacing.

With appropriate boundary conditions, the set of the continuity, momentum, energy and species equations are discretized with the implicit power law scheme in three dimensions and solved using a PISO solver.

The material properties of the base metal and added material are present in Table 2. The data used for calculations are present in Table 3. Due to the mixture of base metal and added powder in the melt pool, the material properties of the solutions are assumed to depend linearly on the material properties of the base metal and added powder [24],

$A_{\text {solu }}=\alpha A_{\text {sub }}+(1-\alpha) A_{\text {add }}$

where $A_{\text {solu }}$ is the thermo-physical property of the solution, $A_{\text {sub }}$ and $A_{\text {add }}$ are the properties of base metal and added material, respectively. In this equation A can be replaced by the density, thermal conductivity, specific heat and viscosity. The mixture fraction element, $\alpha$, is defined the mass fraction of base metal element Fe. The Absorptance of laser beam energy, $\eta_{l}$, is a key process parameter that varies with material composition and temperature. A reasonable estimate of the near-infrared laser energy absorptance is provided by Hagen-Rubens relationship [28]. There, absorptance $\eta_{l}(T)$ is calculated from the

Table 2

Material properties of the base metal and added material [30].

\begin{tabular}{lll}
\hline Property & $\begin{array}{l}\text { Base metal } \\
(38 \mathrm{MnVS})\end{array}$ & $\begin{array}{l}\text { Powder } \\
\text { (Co-Cr-W) }\end{array}$ \\
\hline Solid density $\rho_{s}\left(\mathrm{~kg} \mathrm{~m}^{-3}\right)$ & 7400 & 8400 \\
Liquid density $\rho_{l}\left(\mathrm{~kg} \mathrm{~m}^{-3}\right)$ & 6980 & 6875 \\
Solidus temperature $T_{s}(\mathrm{~K})$ & 1609 & 1598 \\
Liquidus temperature $T_{l}(\mathrm{~K})$ & 1768 & 1754 \\
Solid specific heat $\mathrm{cp}_{\mathrm{s}}\left(\mathrm{J} \mathrm{kg}^{-1} \mathrm{~K}^{-1}\right)$ & 604 & 417 \\
Liquid specific heat $c p_{l}\left(\mathrm{~J} \mathrm{~kg}^{-1} \mathrm{~K}^{-1}\right)$ & 758 & 552 \\
Solid thermal conductivity $k_{s}\left(\mathrm{~W} \mathrm{~m}^{-1} \mathrm{~K}^{-1}\right)$ & 22 & 11 \\
Liquid thermal conductivity $k_{l}\left(\mathrm{~W} \mathrm{~m}^{-1} \mathrm{~K}^{-1}\right)$ & 24 & 13 \\
Latent heat of fusion $L\left(\mathrm{~kJ} \mathrm{~kg}{ }^{-1} \mathrm{~K}^{-1}\right)$ & 270 & 310 \\
Dynamic viscosity $\mu($ Pa s) & $5.5 \times 10^{-3}$ & $5.5 \times 10^{-3}$ \\
Diffusivity D (m $\left.\mathrm{s}^{-1}\right)$ & $4.3 \times 10^{-8}$ & $4.3 \times 10^{-8}$ \\
\hline
\end{tabular}

Table 3

Data used for calculations.

\begin{tabular}{ll}
\hline Parameter & Value \\
\hline Beam radius $r_{b}(\mathrm{~mm})$ & 1 \\
Mass flow radius $r_{p}(\mathrm{~mm})$ & 2.5 \\
Powder catchment efficiency $\eta_{m}$ & 0.9 \\
Powder attenuation efficiency $\eta_{a}$ & 0.8 \\
Convective heat transfer coefficient $h_{c}\left(\mathrm{~W} \mathrm{~m}^{-2} \mathrm{~K}^{-1}\right)$ & 100 \\
Emissivity $\varepsilon$ & 0.7 \\
Angular frequency of the laser $\omega\left(\mathrm{rad} \mathrm{s}^{-1}\right)$ & $1.75 \times 10^{15}[21]$ \\
Permittivity $\left.\varepsilon_{0}(\mathrm{~F} \mathrm{~m})^{-1}\right)$ & $8.85 \times 10^{-12}[21]$ \\
Ambient temperature $T_{0}(\mathrm{~K})$ & 293 \\
\hline
\end{tabular}

temperature-varying electrical resistivity of the base metal material $R_{e}(T)$ by the relation,

$\eta_{l}(T)=\left(8 \varepsilon_{0} \omega R_{e}(T)\right)^{1 / 2}$

where $\omega$ is the angular frequency of the laser radiation and $\varepsilon_{0}$ is the permittivity of free space. Expression for temperature-varying resistivity for liquid $38 \mathrm{MnVS}$ is [29],

$R_{e}(T)=1.125+1.438 \times 10^{-4} T$

\section{Experimental verification}

38MnVS steel (sulfur content $0.04 \mathrm{wt} \%$ ) and Co-based alloy (sulfurfree) are chosen as base metal and added powder, respectively. The material compositions of these alloys are summarized in Table 4. Laserassisted additive manufacturing was implemented on a $1000 \mathrm{~W} \mathrm{Nd}$ : YAG laser manufacturing system (multi-mode laser beam) with six-axis programmed control platform. The beam radius is $1 \mathrm{~mm}$. The laserassisted additive manufacturing experiments were performed in an environmentally controlled chamber with a gas purification system. The chamber was filled with pure argon. Oxygen and moisture content was less than $1 \mathrm{ppm}$. Thus the effect of oxygen is neglected. Samples of the base metal were prepared in the size of $20 \mathrm{~mm} \times 10 \mathrm{~mm} \times 6 \mathrm{~mm}$. In order to measure the concentration of surface-active element sulfur, Auger electron spectroscopy (AES) was performed on a PHI 660 scan Auger microprobe unit. Spectra were obtained for an excitation $5.0 \mathrm{keV}$. The angle between the electron beam and surface normal was $30^{\circ}$. The measurement precision of AES is $0.01 \mathrm{wt} \%$.

\section{Results and discussions}

\subsection{Transient sulfur concentration and Marangoni flow}

Fig. 4(a)-(d) shows the computed concentration profile of sulfur and fluid flow during laser-assisted additive manufacturing at different times. The process parameters are: laser power $700 \mathrm{~W}$, scanning speed $10 \mathrm{~mm} / \mathrm{s}$ and mass flow rate $5.9 \mathrm{~g} / \mathrm{min}$. The concentration is indicated by $\mathrm{wt} \%$. The black arrows in the figures represent the velocity of the liquid metal. The solidus and liquidus temperature are also presented by isotherm. As seen in Fig. 4(a), at 100 ms, only small amount of freesulfur powder is injected into the melt pool, the concentration of sulfur in the melt pool surface is almost equal to the base metal content $(0.04 \mathrm{wt} \%)$. With the moving of the laser beam, more sulfur-free powder is injected into the melt pool. As seen in Fig. 4(b), at $200 \mathrm{ms,}$ the concentration of sulfur is reduced to about $0.026 \mathrm{wt} \%$. With the

Table 4

Material composition of 38MnVS carbon steel and Co-Cr-W powder (weight\%).

\begin{tabular}{lllllllll}
\hline & Fe & C & Co & Mn & Cr & W & V & S \\
\hline 38MnVS & Bal & 0.38 & - & 1.4 & 0.16 & - & 0.5 & 0.04 \\
Co-Cr-W & - & 0.35 & Bal & 1.8 & 12 & 5 & - & - \\
\hline
\end{tabular}



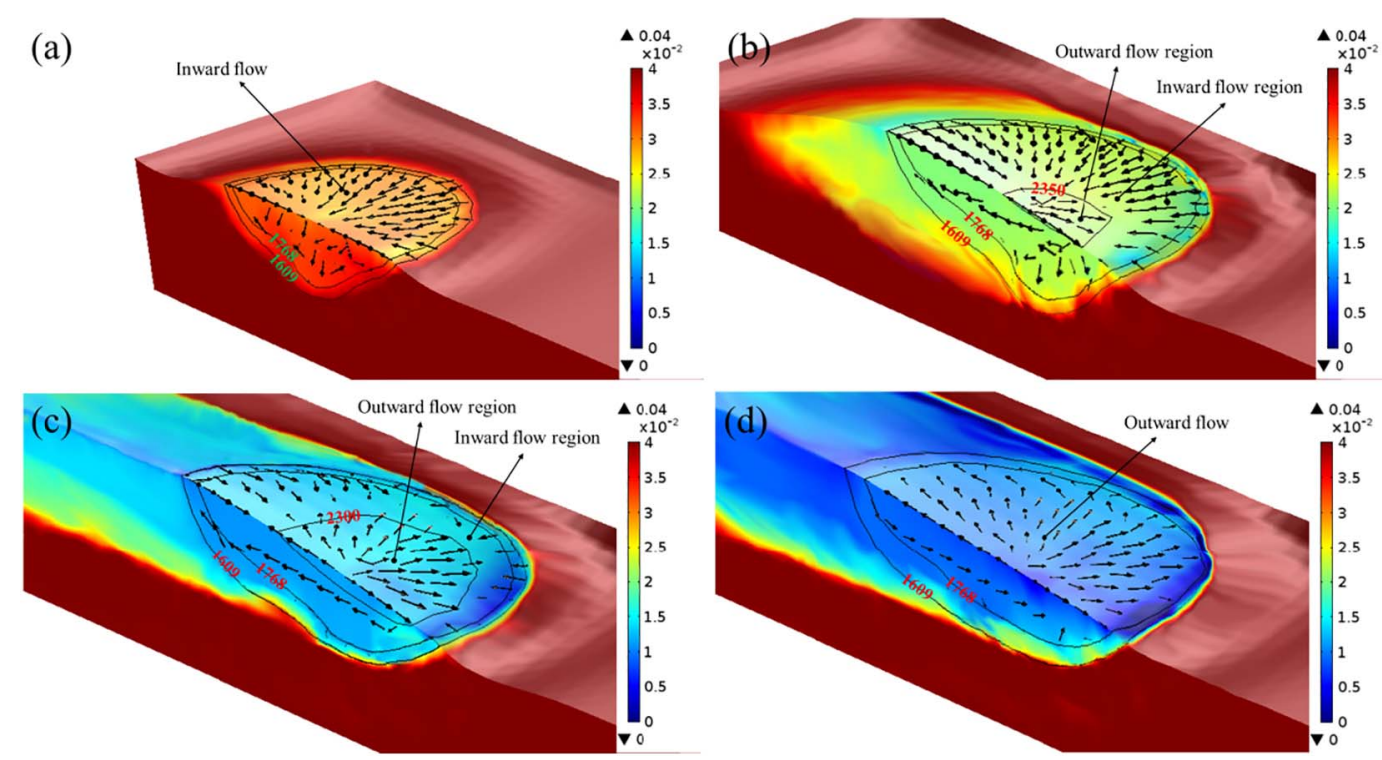

Fig. 4. Computed three-dimensional concentration profiles of sulfur and fluid flow profiles at different times (a) $100 \mathrm{~ms}$, (b) $200 \mathrm{~ms}$, (c) $300 \mathrm{~ms}$, and (d) $400 \mathrm{~ms}$.

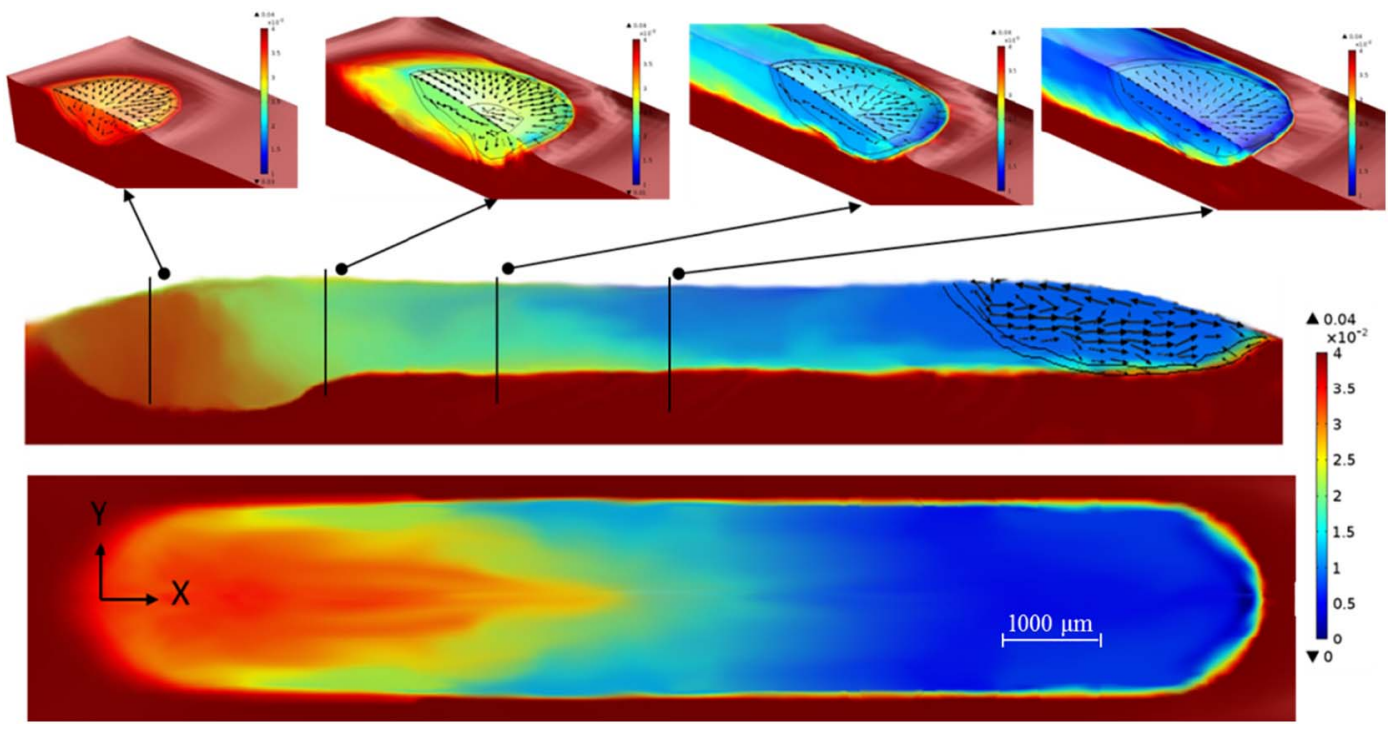

Fig. 5. Concentration profile of sulfur in the longitudinal section.

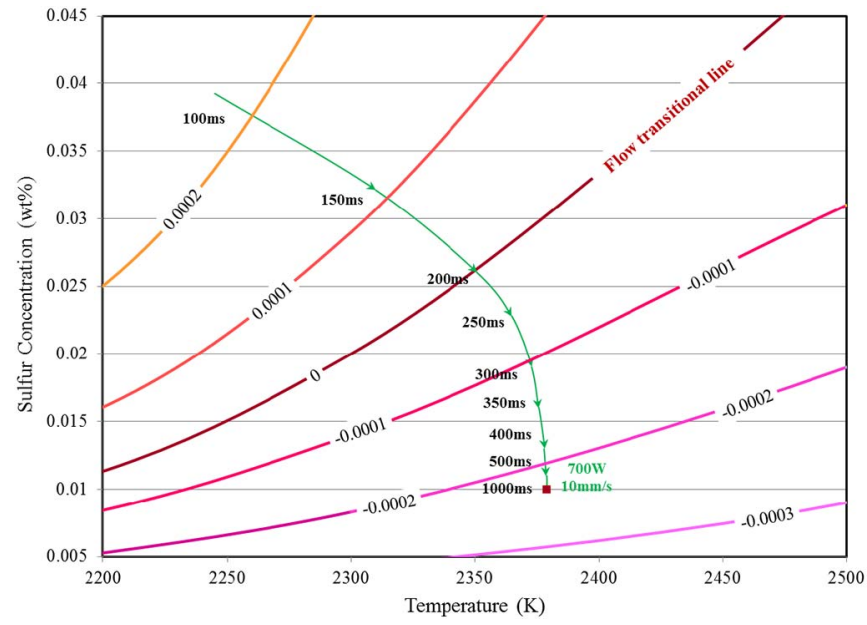

Fig. 6. Variation of the temperature coefficient of surface tension at different temperature and sulfur concentration.

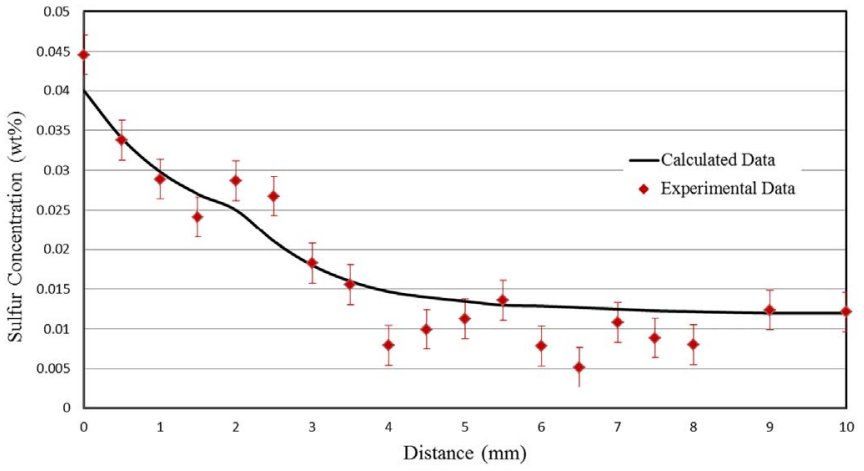

Fig. 7. Comparison between experimental and calculated concentration of sulfur along the centerline of top surface.

mixture of sulfur-free powder and base metal in the melt pool, the concentration of sulfur further reduces as shown in Fig. 4(c). At the time $400 \mathrm{~ms}$ as seen in Fig. 4(d), the sulfur concentration is below $0.015 \mathrm{wt} \%$. The relative importance of thermal surface tension forces 


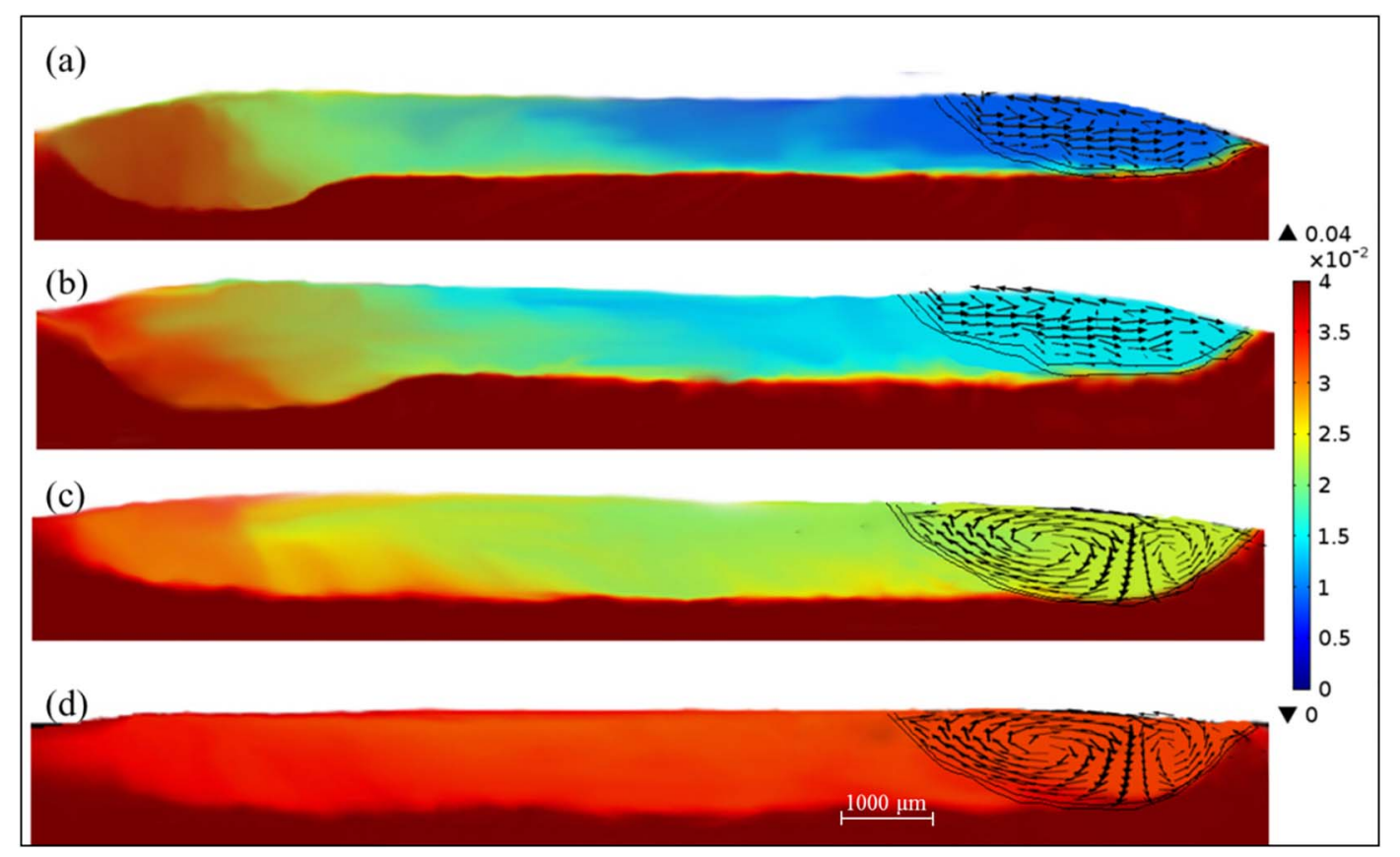

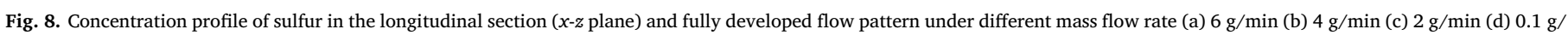
$\min$.

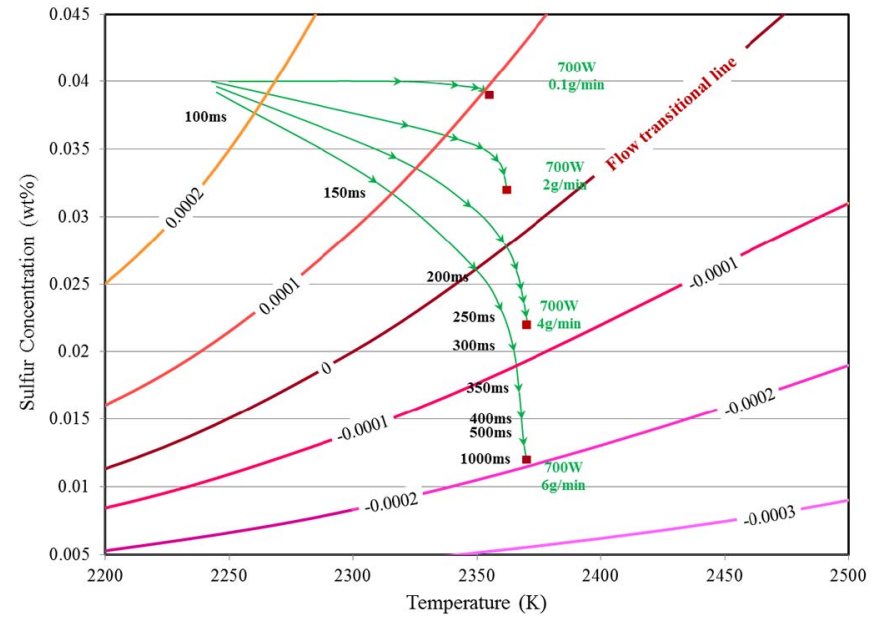

Fig. 9. Variation of the temperature coefficient of surface tension at different temperature and sulfur concentration under different mass flow rate.

and viscos forces in the molten pool is evaluated by Marangoni number,

$\mathrm{Ma}=\frac{d \sigma}{d T} \frac{\Delta T L_{R}}{\mu_{0} \alpha_{0}}$

where $d \sigma / d T$ represents the temperature coefficient of surface tension $\left(10^{-4} \mathrm{~N} \mathrm{~m}^{-1} \mathrm{~K}^{-1}\right.$ in this case), $L_{R}$ represents the characteristic length (laser beam radius, $10^{-3} \mathrm{~m}$, in this case), $\mu_{0}$ is the viscos $\left(10^{-3} \mathrm{~N} \mathrm{~s} \mathrm{~m}^{-2}\right.$ in this case), $\alpha_{0}$ represents the thermal diffusivity $\left(10^{-5} \mathrm{~m}^{2} / \mathrm{s}\right.$ in this case). Thus, the Ma is on the order of $10^{4}$, which means the liquid metal flow in the molten pool is laminar based on some relevant estimations $[5,18]$.

It can be observed that transient variation of sulfur concentration at top surface has remarkable impact on the Marangoni flow within the melt pool. At $100 \mathrm{~ms}$, the Marangoni stress drives the fluid near the top surface inward forming convection currents. The surface flow tends to carry higher temperature fluid from the surface to the bottom of melt pool, result in a deep-penetration region in the central melt pool. At $200 \mathrm{~ms}$, an outward flow region is observed in the center of melt pool, where the temperature of liquid metal is higher than $2350 \mathrm{~K}$. Near the periphery of melt pool, the flow pattern is still inward flow. At $300 \mathrm{~ms}$, since the temperature of melt pool increases, the outward flow region expands. After $400 \mathrm{~ms}$, only the outward flow exists in the melt pool until the melt pool is fully developed. Note that the melt pool shape becomes wide and shallow at time $400 \mathrm{~ms}$. It can be attributed to the outward flow pattern that tends to carry higher temperature fluid from the center of melt pool surface toward the periphery of melt pool. As a supplement, Fig. 5 shows the concentration profile of sulfur in the longitudinal section. The addition of free-sulfur powder into the melt pool decreases the sulfur concentration at the top of melt pool. At the end of the deposition track, the sulfur distribution is almost uniform.

In order to explain the effect of sulfur redistribution on Marangoni flow, Fig. 6 shows that the variation of temperature and concentration affects the surface tension at different time. The isotherms of the temperature coefficient of surface tension are shown in the figure. The calculated temperature and sulfur concentration on the center of top surface at different times are also marked in the diagram. The temperature coefficient of the surface tension $d \sigma / d T$ varies between $-3 \times 10^{-4}$ and $2 \times 10^{-4} \mathrm{~N} \mathrm{~m}^{-1} \mathrm{~K}$. The contour line of $d \sigma / d T=0$ indicates the conditions at which the direction of the Marangoni stress at the top surface of the melt pool changes. On the left upper side of this line, the temperature coefficient of surface tension is always positive, which corresponds to inward flow. On the right lower side of this line, the surface tension temperature coefficient is negative, which corresponds to outward flow. Changes in temperature and sulfur concentration at top surface of melt pool can result in flow reversal if the change results in an excursion cross the flow transition line. As shown in the Fig. 6, at the initial stage of laser-assisted additive manufacturing, the high sulfur concentration and low temperature cause the positive surface tension temperature coefficient and inward flow. As the free-sulfur powder is injected into the melt pool, the sulfur concentration at the top surface decreases, accompanied by temperature of melt pool increases. When the changes in temperature and sulfur concentration result in the excursion cross the flow transition line ( $d \sigma /$ $d T=0$ ), the flow motion transition from inward flow to outward flow occurs. The temperature that flow transition takes place depends on the sulfur concentration. As sulfur concentration decreases, the transition temperature decreases.

In order to verify the calculated results, Fig. 7 shows comparison 

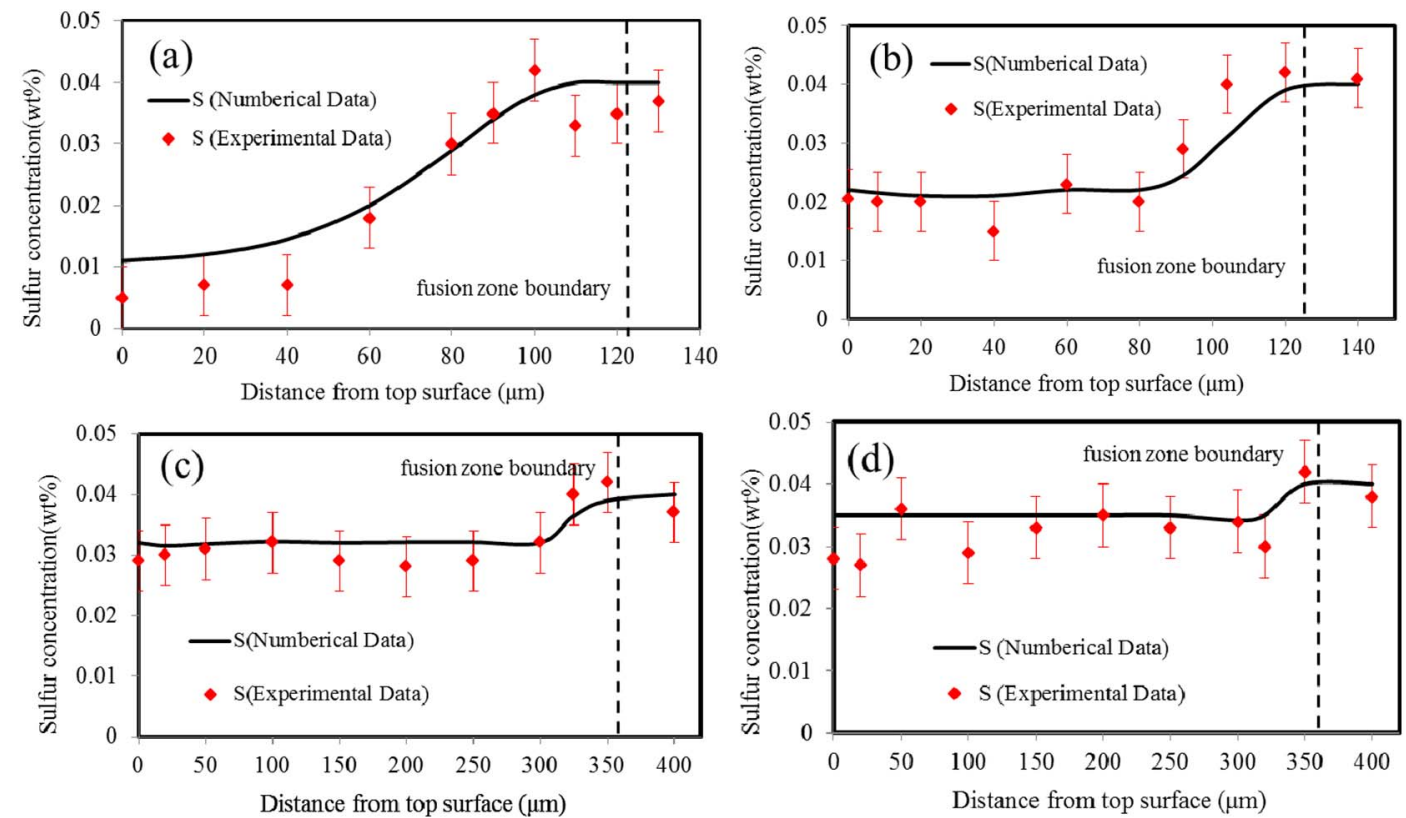

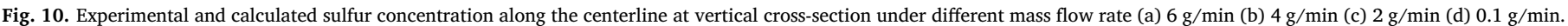
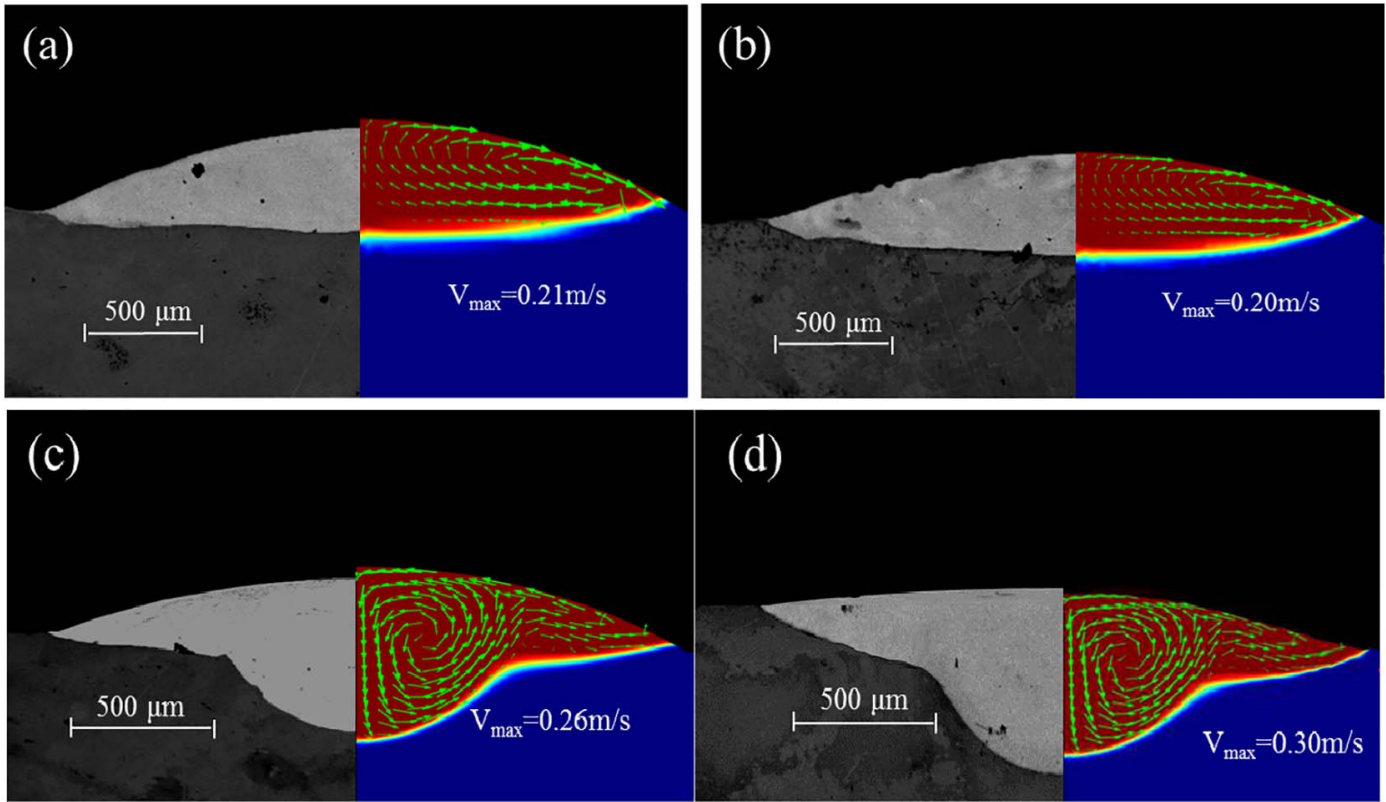

Fig. 11. Experimental and calculated geometry of melt pool ( $y$ - $z$ plane) under different mass flow rate (a) $6 \mathrm{~g} / \mathrm{min}$ (b) $4 \mathrm{~g} / \mathrm{min}$ (c) $2 \mathrm{~g} / \mathrm{min}$ (d) $0.1 \mathrm{~g} / \mathrm{min}$.

between experimental and calculated concentration of sulfur along the centerline of top surface. The calculated sulfur concentration agrees well with the experimental results, which gives strong support for the numerical results and the above interpretation.

\subsection{Transient Marangoni flow under various mass flow rate}

Fig. 8 (a)-(d) shows the concentration profile of sulfur in the longitudinal section and fully developed flow pattern under mass flow rate of $6 \mathrm{~g} / \mathrm{min}, 4 \mathrm{~g} / \mathrm{min}, 2 \mathrm{~g} / \mathrm{min}$, and $0.1 \mathrm{~g} / \mathrm{min}$. The laser power and scanning speed are $700 \mathrm{~W}$ and $10 \mathrm{~mm} / \mathrm{s}$. At higher mass flow rate of $6 \mathrm{~g} / \mathrm{min}$ and $4 \mathrm{~g} / \mathrm{min}$, as shown in Fig. 8(a) and (b), due to the mixture of free-sulfur powder, the sulfur concentration at top surface of melt pool drops rapidly along the scanning direction. Then fully developed fluid flow is outward flow. It is implied that a flow transition from inward flow to outward flow occurs during the process. At lower mass flow rate of $2 \mathrm{~g} / \mathrm{min}$ and $0.1 \mathrm{~g} / \mathrm{min}$, as shown in Fig. 8(c) and (d), the sulfur concentration at top surface drops but reaches the quasi steady state quickly. The flow pattern of melt pool is inward flow in the whole process. The changes in sulfur concentration and Marangoni flow under different mass flow rate can be explained in Fig. 9. Similarly with Fig. 6, the changes in sulfur concentration and temperature at different times under the mass flow rate of $0.1 \mathrm{~g} / \mathrm{min}, 2 \mathrm{~g} / \mathrm{min}, 4 \mathrm{~g} / \mathrm{min}$ and $6 \mathrm{~g} / \mathrm{min}$ are marked in the diagram of the temperature coefficient of surface tension. As shown in Fig. 9, at higher mass flow rate, the sulfur concentration at top surface decreases rapidly. When the sulfur concentration falls below the transition concentration (cross the flow transition line), the flow pattern in the melt pool changes from inward flow to outward flow in that region. At the lower mass flow rate, the sulfur concentration at top surface decreases slowly and reaches the quasi steady state quickly. Less powder and more bulk of base metal are mixed into the melt pool. Since the elemental sulfur is only contained in 


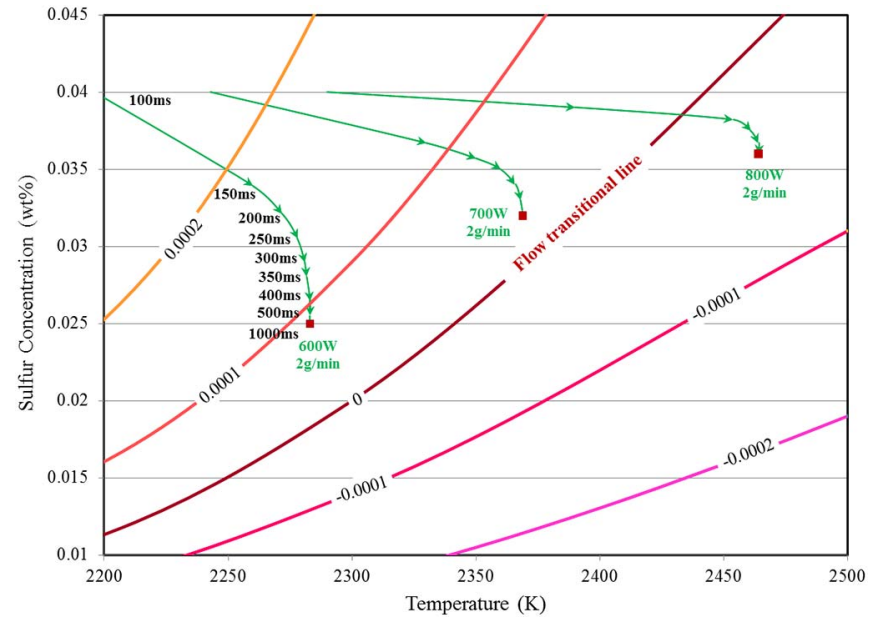

Fig. 12. Variation of the temperature coefficient of surface tension at different temperature and sulfur concentration under energy input.

the base metal, more sulfur transfer into the melt pool. The decrease of sulfur concentration in the melt pool is not enough to make the excursion cross the flow transition line. The temperature coefficient of surface tension is positive throughout the process, causing the flow pattern of inward flow in the melt pool.

Comparisons between experimental and calculated sulfur contents and geometry of cross-section of deposition track are shown in Figs. 10 and 11, respectively. Smaller deviations of computed sulfur concentration and size of melt pool from experimental results are observed. It is mainly resulted from the simplicity of the numerical model. The effect of temperature on the thermo-physics properties is ignored. The laser beam energy and powder flow are considered to be Gaussian distribution. The heat loss due to melting of the powder is neglected. The experimental results give strong evidence for the numerical results. As the mass flow rate decreases from $6 \mathrm{~g} / \mathrm{min}$ to $0.1 \mathrm{~g} / \mathrm{min}$, the sulfur concentration at top surface raises from $0.005 \mathrm{wt} \%$ to $0.035 \mathrm{wt} \%$. Two predominant types of flow pattern in the melt pool are observed under different mass flow rate as shown in Fig. 11. Laser-assisted additive manufacturing under high mass flow rate of $6 \mathrm{~g} / \mathrm{min}$ and $4 \mathrm{~g} / \mathrm{min}$ are shown in Fig. 11(a) and (b), less melting of substrate with larger mass of powder covering the surface of base plate leads to lower sulfur concentration at the top of melt pool. Due to the negative temperature coefficient of surface tension, the flow pattern is outward flow. When the mass flow rate is $2 \mathrm{~g} / \mathrm{min}$ and $0.1 \mathrm{~g} / \mathrm{min}$, due to the higher sulfur concentration at the top of melt pool, the fluid flow is predominantly inwards.

It is worth noting that different flow patterns significant affect the geometry of the melt pool boundary. For outwardly flow pattern as shown in Fig. 11(a) and (b), the melt pool boundary is similar to a hemisphere. The fluid moving away from the central laser beam leads to a wide and shallow melt pool geometry. However, for inwardly flow pattern as shown in Fig. 11(c) and (d), unusual melt pool shapes with multiple inflections in the slope of the boundaries are observed. Higher temperature fluid from the area heated by the laser beam is carried toward the bottom of melt pool, resulting in a deep-penetration region in the central melt pool.

\subsection{Transient Marangoni flow under different energy input}

In order to investigate the effects of energy input on sulfur transport and Marangoni flow, three laser powers $(600 \mathrm{~W}, 700 \mathrm{~W}$ and $800 \mathrm{~W}$ ) were selected. The mass flow rate and scanning speed are $2 \mathrm{~g} / \mathrm{min}$ and $10 \mathrm{~mm} / \mathrm{s}$. Fig. 12 shows the changes in the sulfur concentration and temperature at different times under the different energy input. The isotherms of the temperature coefficient of surface tension are shown in the figure. The variation of energy input has impact on both sulfur concentration and local temperature during the laser-assisted additive manufacturing process. However, the change of melt pool temperature caused by the variation of energy input is the main factor for the flow transition. At lower energy input $(600 \mathrm{~W}$ or $700 \mathrm{~W})$, the temperature coefficient of surface tension is positive throughout the process. The flow pattern in the melt pool is inward in these conditions. However, as the energy input approaches $800 \mathrm{~W}$, the maximum temperature at top surface of melt pool reaches $2464 \mathrm{~K}$. The remarkable increase of temperature changes the temperature coefficient of surface tension from positive to negative, resulting in the flow reversal from inward to outward in the melt pool. Experimental and calculated geometry of melt pool under different energy input (a) $600 \mathrm{~W}$ (b) $700 \mathrm{~W}$ (c) $800 \mathrm{~W}$ is shown in Fig. 13. The experimental results agree well with the numerical results. When energy input increases to $800 \mathrm{~W}$, the deep-penetration region caused by inward flow is vanished. The melt pool boundary becomes a convex circular arc.

\section{Conclusions}

The transient Marangoni flow and mass transport of sulfur in laserassisted additive manufacturing on sulfur-containing base metal are
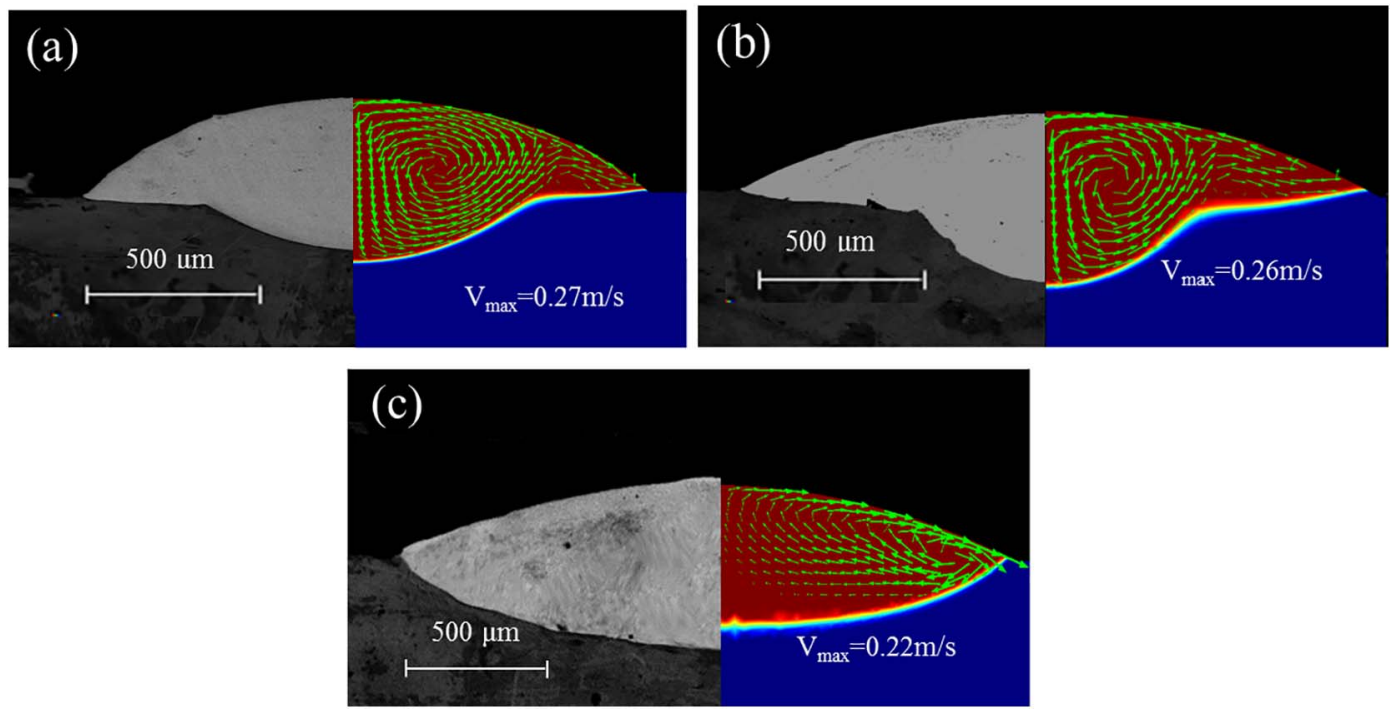

Fig. 13. Experimental geometry of fusion zone and calculated fully developed melt pool (y-z plane) under different energy input (a) $600 \mathrm{~W}$ (b) $700 \mathrm{~W}$ (c) $800 \mathrm{~W}$. 
simulated using an improved 3D transient numerical model. The numerical results on the sulfur concentration distribution and melt pool geometry under different mass flow rate and laser power agree well with the experimental data. Some important conclusions are as follows:

(1) The sulfur distribution in the melt pool is non-uniform and timevarying in laser-assisted additive manufacturing. The sulfur-free powder addition into the melt pool results in the dilution of elemental sulfur in the melt pool. The sulfur concentration along the centerline of top surface gradually decreases. When the local concentration of sulfur is lower than a transition concentration, the temperature coefficient of surface tension changes from positive to negative. The fluid motion transition from inward to outward occurs in that region.

(2) The mass flow rate has remarkable impact on the redistribution of sulfur and the Marangoni flow in the melt pool. With the increase of mass flow rate from $0.1 \mathrm{~g} / \mathrm{min}$ to $6 \mathrm{~g} / \mathrm{min}$, the sulfur concentration at top surface drops from $0.035 \mathrm{wt} \%$ to $0.005 \mathrm{wt} \%$. At lower mass flow rate of $0.1 \mathrm{~g} / \mathrm{min}$ and $2 \mathrm{~g} / \mathrm{min}$, the flow pattern of melt pool is inward flow, resulting in unusual melt pool shapes with multiple inflections in the slope of the boundaries. At higher mass flow rate of $4 \mathrm{~g} / \mathrm{min}$ and $6 \mathrm{~g} / \mathrm{min}$, lower sulfur concentration causes the flow reversal from inward flow to outward flow. The melt pool boundary becomes a convex circular arc.

(3) The change of melt pool temperature caused by the variation of energy input is a significant factor for the flow transition. When energy input increases to $800 \mathrm{~W}$, the increased surface temperature of melt pool results in the negative temperature coefficient of surface tension. The flow transition occurs from inward flow to outward flow in the melt pool.

\section{Acknowledgment}

This work was supported by the National Natural Science Foundation of China under grant nos. 11272316, 11272317 and 11502269.

\section{References}

[1] S.A. David, T. DebRoy, Current issues and problems in welding science, Science 257 (1992) 497-502.

[2] E. Toyserkani, S. Corbin, A. Khajepour, Laser Cladding, CRC, Canada, 2005.

[3] Q. Tang, S. Pang, B. Chen, et al., A three dimensional transient model for heat transfer and fluid flow of weld pool during electron beam freeform fabrication of Ti6-Al-4-V alloy, Int. J. Heat Mass Transf. 78 (2014) 203-215.

[4] Y. Hu, X. He, G. Yu, Z. Ge, C. Zheng, W. Ning, Heat and mass transfer in laser dissimilar welding of stainless steel and nickel, Appl. Surf. Sci. 258 (2012) 5914-5922.

[5] A. Kumar, S. Roy, Effect of three-dimensional melt pool convection on process characteristics during laser cladding, Comput. Mater. Sci. 46 (2009) 495-506.
[6] S. Wen, Y.C. Shin, Modeling of transport phenomena during the coaxial laser direct deposition process, J. Appl. Phys. 108 (4) (2010) 044908.

[7] X. He, P.W. Fuerschbach, T. DebRoy, Heat transfer and fluid flow during laser spot welding of 304 stainless steel, J. Phys. D. Appl. Phys. 36 (2003) 1388-1398.

[8] B. Ribic, S. Tsukamoto, R. Rai, et al., Role of surface-active elements during keyhole-mode laser welding, J. Phys. D. Appl. Phys. 44 (2011) 485203.

[9] L. Zhao, S. Tsukamoto, G. Arakane, et al., Influence of oxygen on weld geometry in fibre laser and fibre laser-GMA hybrid welding, Sci. Technol. Weld. Join. 16 (2011) $166-173$.

[10] C. Winkle, G. Amberg, H. Inoue, T. Koseki, M. Fuji, Effect of surfactant redistribution on weld pool shape during gas tungsten arc welding, Sci. Technol. Weld. Join. 5 (2000) 8-20.

[11] M. Do-Quang, G. Amberg, C.O. Pettersson, Modeling of the adsorption kinetics and the convection of surfactants in a weld pool, J. Heat Transf. 130 (2008) 092-102.

[12] C.X. Zhao, C. Kwakernaak, Y. Pan, I.M. Richardson, Z. Saldi, S. Kenjeres, C.R. Kleijn, The effect of oxygen on transitional Marangoni flow in laser spot welding, Acta Mater. 58 (2010) 6345-6357.

[13] M.J. McNallan, T. Debroy, Effect of temperature and composition on surface tension in Fe-Ni-Cr alloys containing sulfur, Metall. Mater. Trans. B Process Metall. Mater. Process. Sci. 22 (1991) 557-560.

[14] H. Qi, J. Mazumder, H. Ki, Numerical simulation of heat transfer and fluid flow in coaxial laser cladding process for direct metal deposition, J. Appl. Phys. 100 (2006) 024903.

[15] X. He, J. Mazumder, Transport phenomena during direct metal deposition, J. Appl. Phys. 101 (2007) 053-113.

[16] X. He, L. Song, G. Yu, Solute transport and composition profile during direct metal deposition with coaxial powder injection, Appl. Surf. Sci. 258 (2011) 898-907.

[17] X. He, G. Yu, J. Mazumder, Temperature and composition profile during doubletrack laser cladding of H13 tool steel, J. Phys. D. Appl. Phys. 43 (2009) 015502.

[18] Y.S. Lee, M. Nordin, S.S. Babu, et al., Influence of fluid convection on weld pool formation in laser cladding, Weld. J. 93 (2014) 292S-300S.

[19] H. Liu, X.L. He, G. Yu, et al., Numerical simulation of powder transport behavior in laser cladding with coaxial powder feeding, Sci. China Phys. Mech. 58 (2015) 1-10.

[20] Y.J. Zhang, G. Yu, X.L. He, Numerical study of thermal history in laser aided direct metal deposition process, Sci. China Phys. Mech. 55 (2012) 1431-1438.

[21] Z. Gan, et al., Numerical simulation of thermal behavior and multicomponent mass transfer in direct laser deposition of Co-base alloy on steel, Int. J. Heat Mass Transf 104 (2017) 28-38.

[22] P. Sahoo, T. DebRoy, M.J. McNallan, Surface tension of binary metal—surface active solute systems under conditions relevant to welding metallurgy, Metall. Mater. Trans. B Process Metall. Mater. Process. Sci. 19 (1988) 483-491.

[23] S. Asai, I. Muchi, Theoretical analysis and model experiments on the formation mechanism of channel-type segregation, Trans. Iron Steel Inst. Jpn. 18 (1978) 90-98.

[24] A. Bahrami, D.T. Valentine, B.T. Helenbrook, D.K. Aidun, Study of mass transport in autogenous GTA welding of dissimilar metals, Int. J. Heat Mass Transf. 85 (2015) $41-53$.

[25] M.J. McNallan, T. Debroy, Effect of temperature and composition on surface tension in Fe-Ni-Cr alloys containing sulfur, Metall. Mater. Trans. B Process Metall. Mater. Process. Sci. 22 (1991) 557-560.

[26] R.K.C. Chan, A generalized arbitrary Lagrangian-Eulerian method for incompressible flows with sharp interfaces, J. Comp. Physiol. 17 (1975) 311-331.

[27] S. Morville, M. Carin, P. Peyre, et al., 2D longitudinal modeling of heat transfer and fluid flow during multilayered direct laser metal deposition process, J. Laser Appl. 24 (2012) 032008.

[28] J. Xie, A. Kar, J.A. Rothenflue, et al., Temperature-dependent absorptivity and cutting capability of CO2, Nd: YAG and chemical oxygen-iodine lasers, J. Laser Appl. 9 (1997) 77-85.

[29] R.W. Cohen, B. Abeles, Efficiency calculations of thermoelectric generators with temperature varying parameters, J. Appl. Phys. 34 (1963) 1687-1688.

[30] E.A. Brandes, Smithells Metals Reference Book, Butterworths, 1983. 